\title{
Objectile e o projeto paramétrico
}

\author{
Objectile and parametric design
}

\author{
Rovenir Bertola Duarte \\ Universidade Estadual de Londrina, Brasil \\ rovenir@uel.br
}

Louisa Savignon Lepri

UABI Arquitetura e Universidade Estadual de

Londrina, Brasil

Islepri@gmail.com

\author{
Malu Magalhães Sanches \\ Suzuki Arquitetura e Universidade Estadual de \\ Londrina, Brasil \\ malu.msanches@hotmail.com
}

\begin{abstract}
The objectile was a concept developed by Deleuze and Cache in the 80s. It treats the object as a variable and anticipates the society of obsolescence, an inquiry about the contemporary life of the object (marketing, function, representation, modeling, production and consumption). This concept deals with the object where"... fluctuation of the norm replaces the permanence of a law; where the object assumes a place in a continuum by variation" (Deleuze, 1991, p.38). This paper proposes to think objectile as the object of the architectural design, on three types of approximations between design and objectile: (a) Objectile as variable of the design, (b) Objectile as a design variable, and (c) Objectile as architecture (variable architecture). The second approximation (b) enables to discuss the conception of continuous design with power to cross other projects - a meta-design. The main aspect of this meta-design is the variability, another way of control based on concepts of patterns and modulations; however, objectile can mean the release of mind for new types of thought and new kinds of design based on "continuum by variation": meta-design.
\end{abstract}

Keywords: Objectile; parametric design; Gilles Deleuze; Modulado; Digital design.

\section{Introducción}

Desde o último quarto do século XX uma espécie de "crise do objeto" tem aparecido vez ou outra nos debates arquitetônicos, como em escritos de Rowe e Koetter (1980) e, mais recentemente, Hartoonian (2006) e Montaner (2008). Nesta mesma época, mais precisamente em 1983, o francês Bernard Cache questiona "o que é um objeto nos dias de hoje?”. Este arquiteto e teórico propõe “...uma concepção muito contemporânea de objeto tecnológico" (Deleuze, 1991, p.38): o Objectile (object+projectile). E se nos perguntássemos como será o objeto do projeto nos dias de amanhã? Pois, acreditamos que este conceito possa nos ajudar neste caminho.

O objectile surgiu da cabeça do filósofo francês Gilles Deleuze para batizar a pesquisa de Cache e Patrick Beaucé sobre meios industriais de produção de objetos non-standards. Deste modo, este conceito já nasce associado ao digital design e parametria, como também, a um entendimento do objeto na contemporaneidade. Este termo parece trazer um novo valor conceitual para a palavra objeto que, a reboque, ajuda a discutir o objeto do projeto arquitetônico. Será que a vocação do objeto dos nossos processos de projeto consistirá sempre em uma representação de um edifício? Trabalharemos sempre com uma espécie de blueprint ou molde que o edifício deverá seguir para que possa existir?
Esta idéia de molde fixo é colocada em questão com o projeto digital paramétrico, não por acaso alguns autores apontam para uma potencial mudança paradigmática (Carpo, 2011a) (Gane, 2004). Em direção semelhante, o objectile sugere entender o objeto como variável, uma tremenda mudança conceitual. Assim, este artigo trata de refletir, a partir do impacto deste conceito, uma idéia de objeto do projeto paramétrico digital na arquitetura, como também as questões de controle e liberdade.

\section{A vida de um produto: uma idéia de objeto em transformação}

Antes de iniciar esta reflexão sobre o projeto, cabe trazer, ou descrever, uma imagem do objeto na contemporaneidade. Como Baudrillard descreve (2004), vivemos em um mundomarcado por uma imensa flora ou fauna de objetos se sucedendo em ritmo acelerado, e neste mundo o ser humano se assenta diante de gerações de produtos, aparelhos, gadgets vendo-os tornar-se, um a um, obsoletos. Kwinter (2003) explica que o objeto idealizado na modernidade industrial, produzido por e para as massas (Deleuze, 1991), parece desgastar-se rapidamente neste ambiente. Este objeto, que foi baseado na constância da lei para sua fabricação em série, agora conflita com a velocidade e variabilidade da época contemporânea. Para Cache, um diferente objeto emergiria baseado em um novo contrato "...sobre a sua utilização ou produção" (1995, p.95), onde o 
“...objeto idêntico seria um tipo de contrato não mais viável” (Kwinter, 2003, p.99). Para entender melhor esse novo contrato sobre a utilização e produção do objeto, podemos seguir a reflexão que Cache (1995) propõe sobre a vida de um produto tecnológico na atualidade.

Cache divide a vida deste produto em seis fases: marketing, função, representação, modelagem, produção e consumo. Antes de tudo, o produto nasce da convivência entre uma sociedade que clama intensamente por personalização e sua limitação no atendimento desta individualização, por esta razão o produto necessita flutuar sobre uma curva de variação. Não busca a massa nem o individuo, mas através de customizações o produto tenta alcançar um conjunto mais indefinido e nebuloso. Desta necessidade de variabilidade, o marketing surge para produzir imagens, que parecem referirse ao produto, mas na verdade mostram que o produto é sim em primeiro lugar a própria imagem, como podemos ver na proliferação atual das logomarcas. Por outro lado, marketing e função se entrelaçam, pois o primeiro concebe e fabrica no usuário o efeito e desejo a respeito do segundo. Assim, a função também se aproxima cada vez mais da variação, até mesmo porque com a manipulação numérica de dados digitais, um objeto pode ter o mesmo código de outro. Uma fachada de edifício pode desejar ser imagem ou uma música - como na Hyposurface do dECOi (Figura 1).

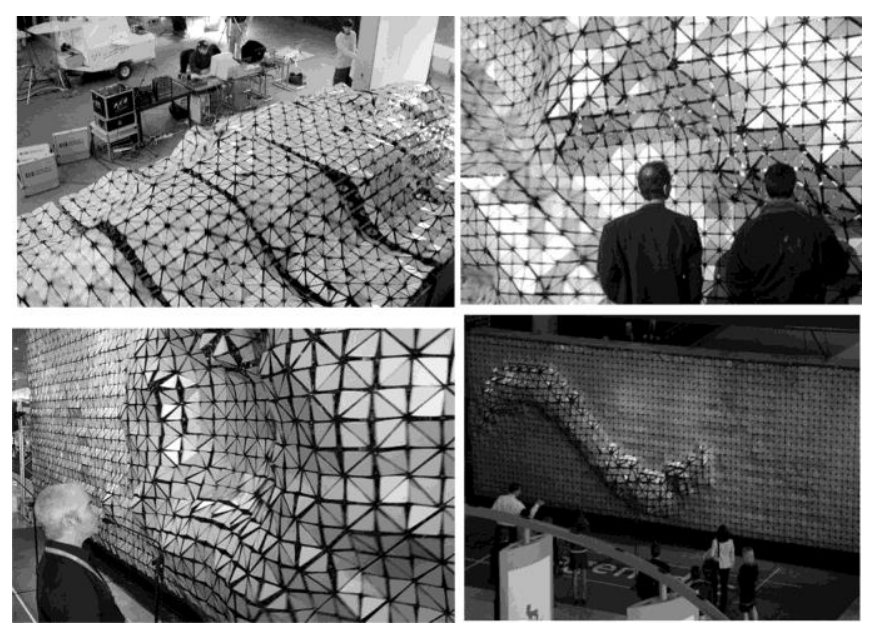

Figura 1:Hyposurface do dECOi

http://www.hyposurface.org/

Este conceito de produto, que nasce sob a sombra da ameaça de um prejuízo possível, imprime sua variabilidade também na sua modelagem. Esta não é mais baseada em um molde como o objeto industrial, pois não repete um único modelo fixo, mas sim, acontece a partir da interseção de algumas restrições e parâmetros. Assim sua representação precisa revelar a mesma variabilidade e maleabilidade, mostrando o objeto sendo calculado em tempo real ao invés de projeções congeladas. Cache (1995) fala sobre uma geografia das possibilidades plasmada em uma imagem CFAO (Conception et Fabrication Assistées par Ordinateur). A produção que, como dissemos, não pode ser realizada através de um molde fixo e forma predefinida, também reflete tal variação através de uma modulação interpretada por máquinas de controle numérico. Esta modulação garante uma gama de pequenas mudanças e customizações que, de alguma forma, reflete a própria curva de oferta e procura introjetada no produto. Aqui vemos mais claramente a mudança de contrato vigente, uma associação contemporânea entre o homem e o objeto não mais baseada na estandardização e na lei da constância.

Esta descrição da vida do produto por Cache revela um produto fustigado pela variabilidade em suas diversas fases. Ele toca a sociedade de consumo atual que, tomando a expressão de Carpo (2011b), vive uma espécie de "paradigma da variabilidade", onde mudança parece fundamental para alcançar satisfação. Gane (2004) observa que a sociedade está mais insistente na busca de personalização, onde noções como satisfação e qualidade parecem ser conseguidas por meio de opções de escolha. Nesta sociedade, a velocidade do consumo e das flutuações de comportamento tem transformado o conceito de objeto, deixando-o inconsistente. Aqui entra o objectile que pode tratar de uma idéia de objeto mais compatível com o dinamismo desta sociedade ligada ao consumo e a obsolescência (Figura2). Este objeto não trata da materialização simples de uma entre diversas variações, mas ele torna a própria variação. Como seria pensar o projeto baseado nesta idéia de objeto variável? Gane em 2004, perguntando-se se o projeto paramétrico seria "a paradigm shift?', observa que o arquiteto estaria buscando novas abordagens para concepção que o permita explorar a variedade e que o mantenha em harmonia com a sociedade. O objectile e a parametria poderiam ajudar a entender essa aspiração de transformação do projeto? Antes de prosseguirmos, cabe entender melhor o que seria objectile.

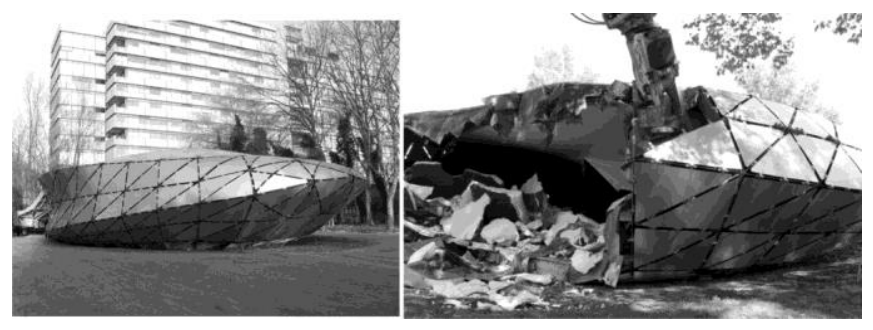

Figura2: Como outros produtos a arquitetura também revela esta ideia de obsolescência. Edificio iWEB de ONL. iWeb | VAA.ONL

\section{Origem do conceito Objectile e sua relação com a parametria:}

Essa idéia de objeto variável tem uma interessante raiz na filosofia do século XVII de Gottfried Leibniz. O curioso é ela ter germinado justamente no século XVII, enquanto René Descartes reinava com seus conceitos res cogitans ("algo que pensa", o sujeito) e res extensa ("coisa extensa", tudo que está determinado em alguma forma). Os conceitos de Descartes, em consonância com a teoria do conhecimento aristotélica baseada no sujeito-objeto, provocaram Leibniz a mudar radicalmente a idéia de objeto (Montefameglio, 2016). Este alemão fala sobre a existência de uma matéria caótica com natureza confusa, onde o res extensa seria insuficiente, pois o objeto não estaria mais definido por uma forma essencial e não seria bem determinado. Como observa Montefameglio (2016), não significa que não existam objetos para Leibniz, mas que seu estatuto mudou, eles seriam um ato em movimento, ato de mudança, um ato transformador, como explica Deleuze (1991), "puro evento". 
Essa concepção foi inspiração para Deleuze e Cache para o objectile, um objeto variável que não podemos definir por meio de leis regulares fixas, como a geometria clássica, ao contrário, precisamos de movimento. Nas palavras de Deleuze "...a flutuação da norma substitui a permanência de uma lei, quando o objeto ocupa lugar em um contínuo por variação" (1991, p.38). Um único objectile trata de muitos objetos em potência, incorporando assim a variabilidade. Nilsson (2007) explica que em termos aristotélicos, trata-se de muitos objetos, em termos deleuzeanos, um objectile, uma forma em muitos eventos possíveis. Deleuze destaca que objeto neste caso não seria uma forma essencial, mas uma superfície variável como uma espécie de família "enquadrada por parâmetros" (1991, p.38). Carpo (2011a), tomando o mesmo rumo, ressalta a questão dos parâmetros na definição do objectile: uma infinita variedade de objetos, todos distintos a partir de alguns parâmetros e semelhante frente outros. Objectile foi relacionado por Deleuze (1991) com uma função matemática, alcança "pura funcionalidade", assim, igual a uma equação, resumidamente trata de parâmetros e variáveis.

Os "parâmetros" especificam os termos passíveis ou não de variação da equação $(a x+b y+c z+d=0 ; a, b, c$ e d são parâmetros), como lembram García e Jofre (2012), normalmente associados a uma magnitude modificável. Gane (2004) destaca que estes parâmetros devem ser mensuráveis, do tipo quantitativo ou qualitativo, como temperatura, pressão, distância, ou de um conjunto de medidas como o estado de emoção de um indivíduo (alegria ou tristeza). Assim, o parâmetro é o elemento que define um sistema e determina ou limita o seu desempenho e a variável $(x, y, z)$ trata da gama de maleabilidade que esta função pode alcançar. Além destes dois fatores também são importantes a modulação e associação. $\mathrm{O}$ intervalo entre limites destas variáveis seria a modulação (temperatura em $x$ de $0^{\circ} \mathrm{C}$ a $20^{\circ} \mathrm{C}$ ) e a associação a relação entre os parâmetros para dar lógica a equação ("a" que se relaciona com "b" e com "c"). Neste sentido, o objectile e projeto paramétrico tratam dos mesmos elementos: parâmetros, variáveis, modulações e associações; todos relacionados com a idéia de variabilidade citada anteriormente.

García e Jofre (2012) nos lembram que o projeto paramétrico vai além do simples emprego de parâmetros, afinal toda operação de desenho digital usa parâmetros. Eles explicam que o projeto paramétrico seleciona valores variáveis em um modelo, um tipo de raciocínio codificado ligado a um documento e a um processo de modelagem, podendo ao final dar suporte à fabricação de um sem número de componentes diferentes. Para Nilsson (2007) o uso de parâmetros no processo de projeto torna possível contextualizar o objeto arquitetônico e torná-lo ajustável às situações em que ele deve funcionar. Neste sentido não trabalhamos com um objeto fixo, mas com um objeto variável dentro de parâmetros específicos e orientados por certa modulação. Por esta razão, Gane (2004) destaca que o projeto paramétrico é marcado pelo processo de escolha de parâmetros e restrições relacionadas com um problema de projeto, todos associados de algum modo (por exemplo, a inclinação de um brise vertical associa-se à orientação de um edifício). Esses parâmetros, variáveis, modulações e associações estarão em um modelo que, o mais interessante, poderá ser usado para explorar diferentes alternativas de solução de projeto e em diferentes trabalhos. O projeto assim funciona como um objectile já que carrega em um só modelo diversos objetos, em linguagem de
Leibniz, um objeto que se desdobra em muitos: um objeto variável. Vejamos como esse tipo de objeto aproxima-se do processo de projeto.

Aqui apresentamos alguns tipos de aproximação segundo a permanência e materialidade do objectile dentro do projeto:

(a) Objectile como variável do projeto (ferramenta morta projeto tradicional incrementado): Neste caso o objeto variável será aplicado em um momento do projeto com a finalidade de encontrar uma única solução adequada, para então congelarmos as opções. Assim, a multiplicidade de suas variáveis manter-se-á viva até a escolha de uma solução específica, em seguida matamos o objectile. Essa aproximação o incorpora no processo mais tradicional de projeto, não por casualidade, os exemplos levantados por García e Jofre (2012) sobre a origem do projeto paramétrico, com Gehry e Grimshaw, tratam de emprego da variabilidade para o "controle da forma". Exemplo podem ser dados com Studio Gang no Aqua Tower ou Amanda Levete no Hills Palace (Figura3).

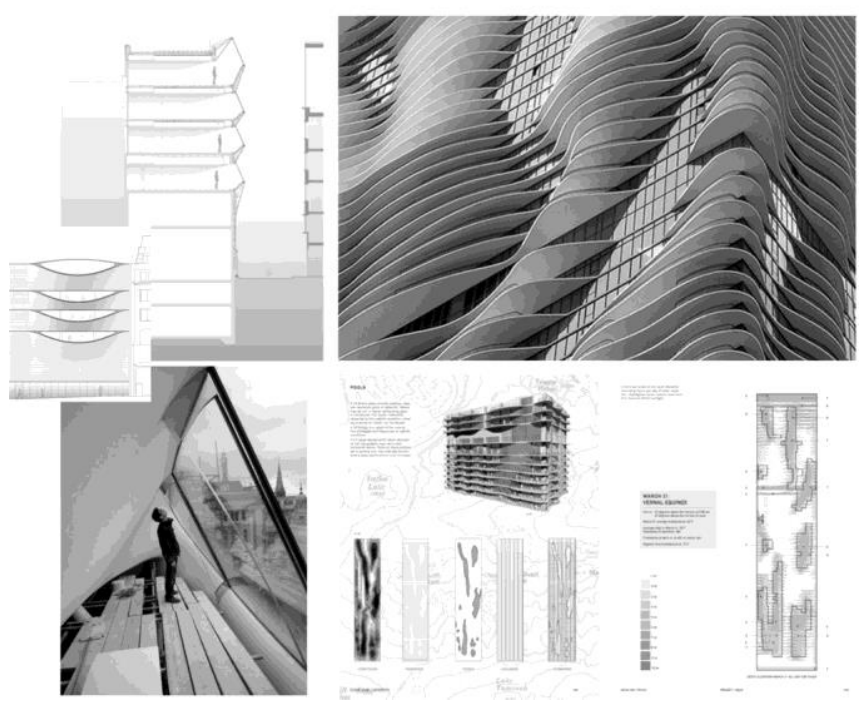

Figura 3:Objectile como variável do projeto, Studio Gang no Aqua Tower ou Amanda Levete no Hills Palace

www.pinterest.com

(b) Objectile como projeto variável (ferramenta viva metadesign): Nesta aproximação o projeto se concentrará na própria variabilidade do objeto, em lugar de pensarmos em uma única solução mais adequada, trataríamos com uma gama de soluções e suas modulações. Neste caso, o objectile se manteria vivo, inclusive para outros projetos, devido a sua capacidade de gerar um sem número de possibilidades. Nesta categoria, o projetista pode, por exemplo, associar o objectile a variáveis para customização (caso da Variomatic house de ONL ou a arquitetura de Arquiteto Ming Tang), ou a tipos de conceito que serão reaplicados em projetos distintos (caso dos Design Models do UNStudio, ver Duarte,2015) (Figura4). 
Pode ser pensado como um esqueleto paramétrico modulado (Gane, 2004) ou um primitivo variável Trummer (2011).

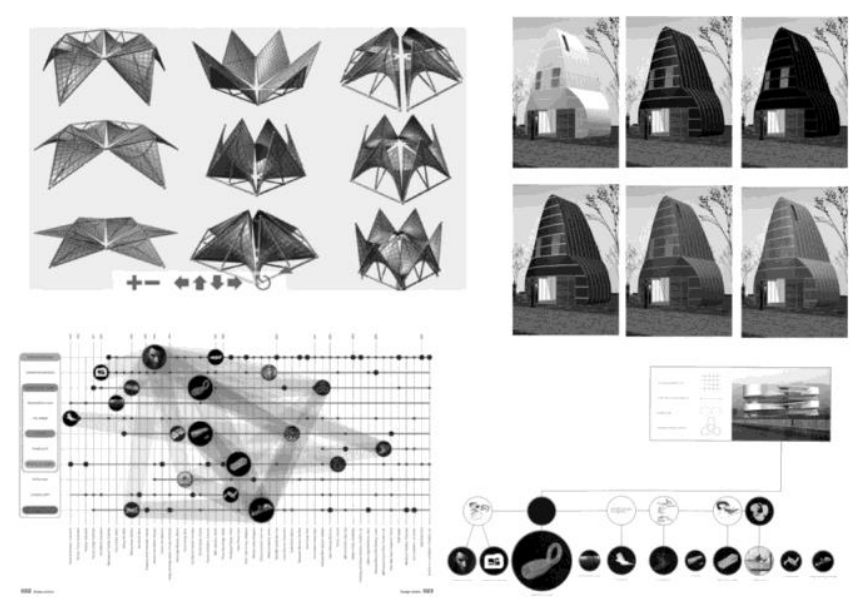

Figura 4: Objectile como projeto variável, Variomatic house de ONL ou a arquitetura de Arquiteto Ming Tang e Design Models do UNStudio

Duarte, 2015 e www.iaacblog.com

(c) Objectile como arquitetura (arquitetura variável): Neste último caso o objectile será materializado de alguma forma, sem perder suas variáveis. Para Nilsson (2007), trata-se de um novo tipo de tectônica, cuja oportunidade seria construir novas relações com o corpo, muito além do consumo visual do espaço. Aqui o objectile não se resume ao projeto, obrigando o homem a produzir uma percepção mais dinâmica e interativa. Contudo, esta aproximação envolve uma evolução tecnológica e um caminho novo a ser trilhado, assim é marcada por atividades mais de vanguarda, como os trabalhos do protoSPACE coordenadas por Kas Oosterhuis (Hyperbody - TUDelft), Media-TIC building de Cloud 9 (Enric Ruiz Geli) e o, já consagrado, exemplo do Pavillion Water do NOX (Figura5).
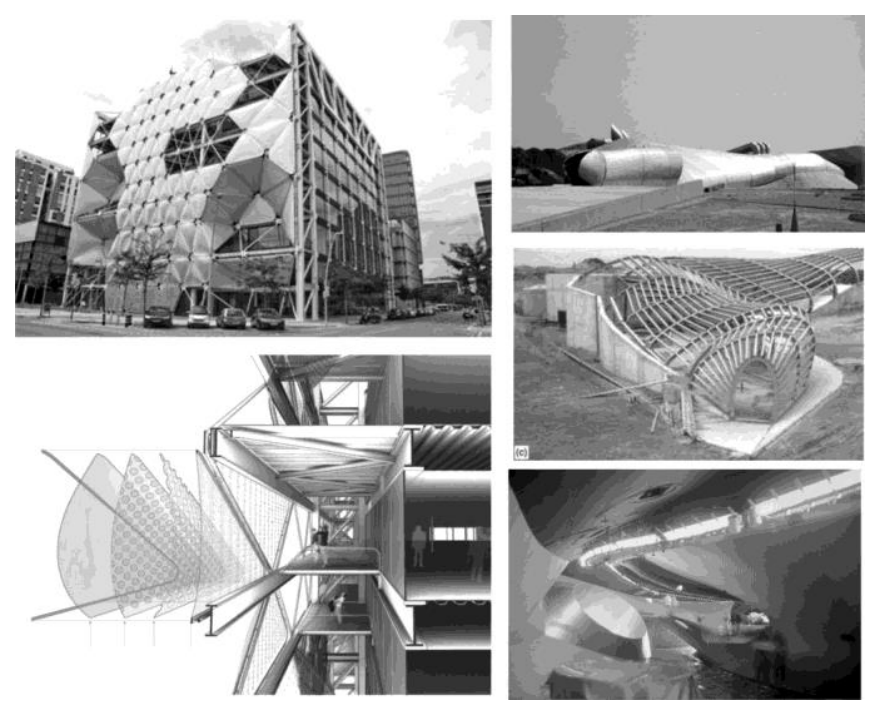

Figura 5:Objectile como arquitetura, Media-TIC building de Cloud 9 e Pavillion Water do NOX

$$
\text { www.pinterest.com }
$$

Interessa-nos aqui para reflexão do processo de projeto o potencial transformador da segunda aproximação (b), pois a primeira (a) acaba aproveitando-se parcialmente do potencial da variabilidade, matando-a em sua absorção pelo projeto tradicional, enquanto na terceira (c) seu foco vai além do próprio projeto, tateando uma nova arquitetura. Neste segundo caso, o projeto se concentra menos na concretização da forma, mas como observa Carpo (2011a), um pensamento baseado na transmissão de algoritmos invisíveis ao invés das formas visuais. Ainda que o italiano detecte um paralelo histórico com as ordens albertianas, ele destaca que nossa época atual lida com a passagem do mundo mecânico para o eletrônico. Esta passagem trata da mudança da produção de objetos para a produção de simples seqüências de números que por sua vez geram objetos (Carpo, 2011a). Assim, o projeto neste caso não se concentraria em produzir um objeto bem delimitado, em outras palavras, rejeita uma representação que congela as variáveis não eleitas para construir um molde em formato de desenhos blueprint. Carpo alerta que nenhum produto final de qualquer processo digital é realmente final, apenas um produto ocasional de um processo algorítmico que poderá gerar muitos outros, ou seja, o objectile como uma mudança de paradigma projetual.

Essa idéia de um produto não finalizado, que nos faz relacionar com meta-processos de projeto (Duarte, 2015), poderia ser pensado como um modelo que ajudaria a orientar o projetista em caminhos e momentos diversos. Aqui teríamos que imaginar um tipo de projeto que se faz sem um fim muito específico, "pura funcionalidade", que possa transcender os conceitos de início e fim de projeto. Uma espécie de objeto de um projeto continuado, que poderá ser útil de muitos modos, pois dotado de uma forma flutuante (não definida), trabalharia dentro de uma faixa variável modulada, podendo atravessar diversos outros projetos (Figura6). O objectile iria além do conceito de reciclagem de uma idéia, pois modula além de ciclos definidos, teria o potencial de entrar e sair a qualquer momento do processo porque não é definido, é muitos em um, dando condições de uso não linear. Neste sentido, trata de um tipo de projeto que se constrói temporalmente, em harmonia com a flutuação do comportamento do mundo contemporâneo e sua demanda por escolhas para satisfação e contentamento. Estas escolhas estão diretamente relacionadas com as variáveis do projeto paramétrico, desta forma seguimos com o aprofundamento de Gane sobre o assunto. 


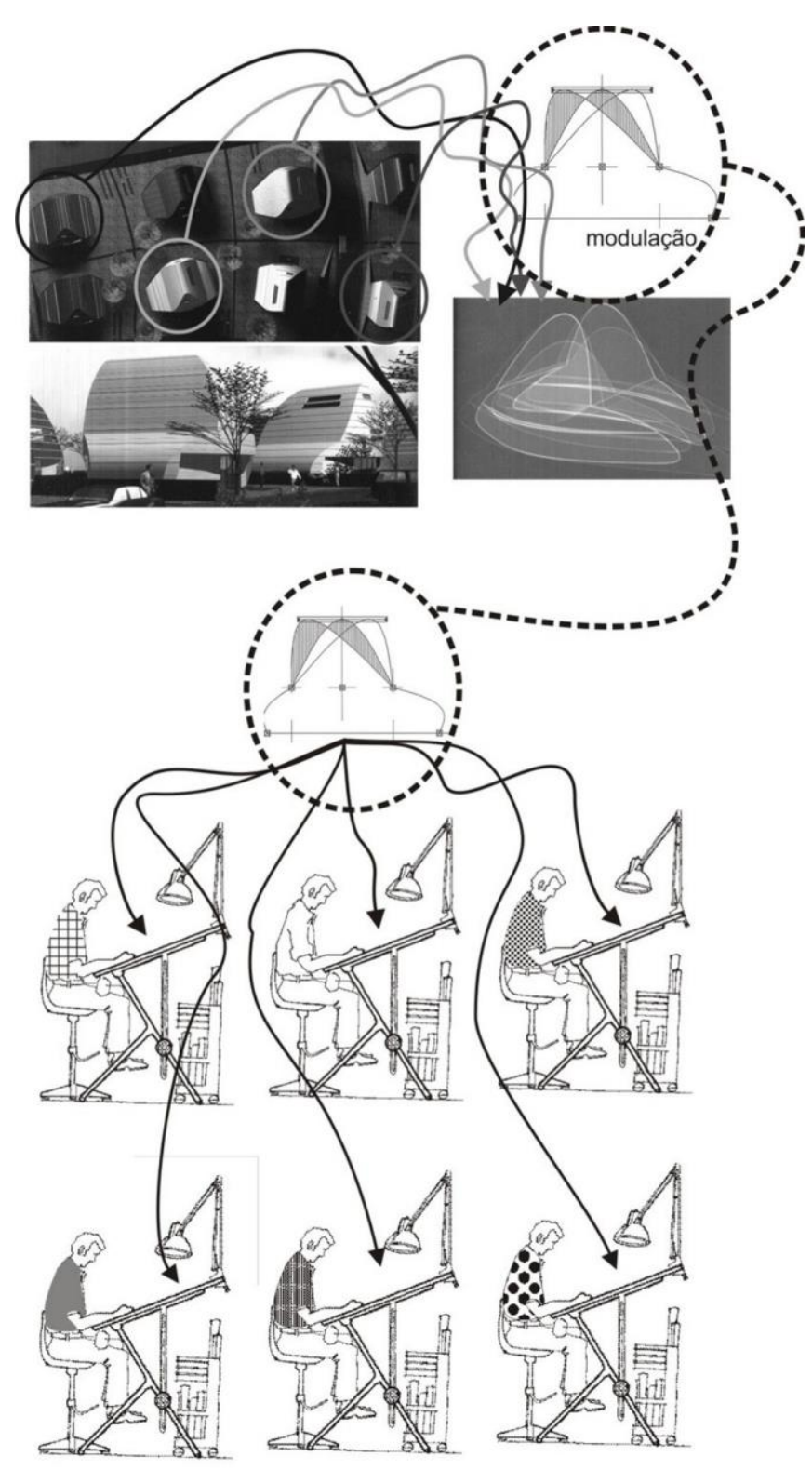

Figura 6:Objectile como meta-processo, atravessando por diversos trabalhos

Imagem produzida pelo autor

\section{Controle e liberdade: a questão das variáveis no projeto paramétrico}

Todo processo de criação lida com uma gama infindável de parâmetros e variáveis, então o projetar inicia com a redução destes a partir da circunscrição de um ou diversos problemas. O americano Gane (2004) destaca algo fundamental, que toda racionalização de um projeto começa com uma simplificação dos seus componentes, um modo de obter controle, pois sem esta simplificação inicial a mente humana ficaria sobrecarregada e descontrolada. Não por acaso, Gross (1986) define projeto como um modo de explorar restrições. De modo semelhante, ainda que pautado nas variáveis, o pesquisador Gane elenca três componentes do processo de projeto diretamente relacionados com este controle e simplificação: regras, variações e ambiguidades.

Inicialmente o projetista necessita construir um sistema, como todo trabalho artístico, com o objetivo de nortear a criação e definir normas para as relações de seus componentes. Gane destaca que esse é o papel das "regras", assim cabe ao projetista decidir qual regra será dominante e que refinará o resultado do projeto, ainda que este processo muitas vezes seja um pouco confuso e aleatório. Neste momento, estruturas organizacionais, orientações solares, hierarquias entre alturas de blocos ou qualquer outro aspecto pode ser considerado essencial para definir restrições e associações entre parâmetros, ou seja, produzir controles.

Por outro lado, se a regra restringe os componentes, as variáveis são fundamentais, pois sem elas o projetista chegará rapidamente a um impasse na sua tomada de decisão. Assim, todo processo de projeto trabalha com uma gama de variações, que podem ser mais aleatórias (Blind Variations) ou que tentem aprofundar a investigação do problema. Esse segundo tipo de variação é o mais importante para o processo de projeto, porque tenta entender e construir as relações entre os diversos parâmetros. Gane (2004) destaca duas variações deste tipo, as por intuição (Insight) e as por análise gradual (Gradual Analysis), ou seja, com menos ou mais sistematização e controle na investigação das associações entre parâmetros. Na primeira a visão é mais global (algo como top-down) e na segunda vai crescendo a complexidade (algo como bottom up). Além das regras, as variações também carregam outro tipo de controle, trata-se das restrições definidas pela modulação, isto é, a faixa de tanto até quanto, poderá variar um parâmetro específico. Desse modo, as variações trazem junto de si valores e prejulgamentos essenciais para o jogo do projeto, pois dirão modulações entre máximos e mínimos que permitirão pensar melhor relações entre diversos subproblemas (aqui uma modulação na orientação do edifício, poderá ajudar na definição da rotação do brise vertical). Algo que funciona muito bem como estratégia quando não sabemos exatamente onde poderemos chegar.

Esse controle das variações é bem-vindo porque ajuda na construção das relações, ficando mais fácil pensar, por exemplo, em uma janela que trata de iluminação e ventilação, ao mesmo tempo em que interfere na funcionalidade interna de um ambiente e na composição estética da fachada. A modulação aumenta o controle sobre um jogo de opções flutuantes que possuem algum tipo de relação (definindo, por exemplo, uma faixa de $0.8 \mathrm{~m}$ a $1 \mathrm{~m}$ de paredes laterais internas, para não interferir na funcionalidade). Estes dois conceitos, modulação e controle, tornam-se essenciais para pensarmos sobre objectile e o projeto paramétrico, contudo não devemos nos esquecer do último elemento de Gane: a ambigüidade. Este último elemento introduz a surpresa através de meios que não são inteiramente do controle do projetista, pois desde este último elemento a regra pode conter mais de um caminho. É verdade que geralmente o emprego das regras busca reprimir a ambigüidade e controlar as variáveis, mas a invenção sempre desafia a estabilidade do projeto e introduz 
um tipo de liberdade. Ao final, em prol de mais controle, a "modulação temporal" segue como um caminho para explorar o movimento entre as diversas trajetórias de associações e combinações, faz com que uma matemática assuma a variação como seu objetivo (Deleuze 1991).

\section{O controle: a idéia de modulado}

O conceito de modulado, que estamos falando desde o começo do artigo, foi pensado por Deleuze (2007) inspirado na visão do filósofo Gilbert Simondon sobre analogias. Este autor discute três tipos de transporte de informação na geração da forma: molde, módulo e modulado. Para entender o "molde" pode-se pensar em um balde de areia de praia que imprime a similaridade de suas ranhuras na areia, funcionando de fora para dentro. Basta alcançar o estado de equilíbrio, e aí, desinformamos. O "módulo", ao contrário, trata das relações internas, como um molde interno, um movimento de dentro para fora, como ossos de um esqueleto que auxiliam na definição da forma de um corpo ou como um grid orienta um edifício. Por fim, o conceito mais relevante aqui, a "modulação" trataria de uma espécie de molde variável, que não pára quando alcança o equilíbrio e continua a modificar o molde. "Um modulador é um molde temporário contínuo" (Simondon Apud Deleuze, 2007, p.156). Esse modulador controla as variações dos diversos objetos presentes simultaneamente no objectile.

Savat (2009) busca aprofundar essa idéia de modulação desde um texto "Post-Scriptum sobre as Sociedades de Controle" onde Deleuze (1992) trata da passagem da sociedade disciplinar para a sociedade de controle. Este autor coloca a modulação dentro do seu contexto social, um tipo especial de controle, onde as pessoas não necessariamente percebem que suas ações estão sendo observadas e registradas através da amplificação dos bancos de dados. Estamos sendo modulados! Essa nova sociedade observa a partir do reconhecimento de padrões, como diz Bogard, um modo de observação que vê antes do fato (apud Savat, 2009). Uma sociedade marcada pelo anseio de programar-se com antecedência, onde se planejaria trajetórias e confirmaria qual perfil humano combinaria com elas. Ainda que possam existir moldes, enquanto houver esta modulação constante, nenhum modelo poderá aderir fortemente nestes moldes.

Deleuze (1992) exemplifica com o ensino continuado que tende a substituir a escola. No lugar do ensino disciplinar, segmentado claramente (com início-fim, organizado em séries, com etapas fundamental-básico, com segmentação e definição de atividades), trata de um ensinamento que nunca acaba, onde o controle contínuo substitui o exame (não pára quando alcança o equilíbrio e continua a modificar o molde). Podemos estabelecer um paralelo com a idéia de metadesign, como explica Fischer e Herrmann (2015), ele é caracterizado como "o projeto para o projeto depois do projeto". O metadesign é baseado na suposição de que usos e problemas futuros não podem ser completamente antecipados no momento da concepção, estimulando que os usuários se tornem co-designers a tempo de uso ("usersas designers"). Esta concepção de projeto demanda maior possibilidade e maleabilidade de estruturas e processos, suportados ou influenciados pelos meios computacionais (Fischer e Herrmann, 2015). Em outras palavras, concentra-se em um quadro de estruturas e processos, em vez de objetos definidos e conteúdos fixos, a semelhança com objectile é nítida.

Para pensarmos melhor sobre esta idéia de projeto continuado na sociedade do controle, cabe uma reflexão sobre o que Savat (2009) chamou de "mecanismos da modulação": reconhecimento de padrões, antecipação das atividades, programação de fluxos e a amostra. Diferente da sociedade disciplinar de Foucault, a modulação não se concentra nos corpos individuais (como um projeto específico), senão no reconhecimento de padrões que os moldam continuamente. Em paralelo, o projeto baseado no objectile não visa controlar a forma como um molde bem definido, parece mais com uma peneira "cuja trama varia de um ponto ao outro" (Deleuze, 1992, p.221), procura padrões gravados no intervalo de variação. Outro mecanismo trata da antecipação da atividade, pois o objectile, mesmo antes de saber para qual será seu fim preciso, necessita modular as possibilidades. Por outro lado, como explica Savat esse mecanismo permite o acesso dos dados em qualquer ponto, sem a necessidade de ler o código inteiro do começo ao fim. Continuando a comparação, sugerimos que o objectile seja concebido de tal modo que possa entrar em um momento qualquer do processo de projeto, desligado das sequências processuais ali existentes. Em função da exigência de antecipar as atividades, a modulação tende a utilizar os instrumentos de modelagem numérica de computador visando cartografar os fluxos. Por fim, como explica Deleuze (1992), no lugar de massas, este mecanismo lida com amostras, o objectile não se preocuparia em definir-se e colocar-se a teste, carrega com ele apenas uma amostragem de possibilidades baseada em padrões. As amostras não necessitam de consciência, não por acaso são elas as utilizadas para determinar os padrões de consumo (Deleuze, 1992).

Por esta razão a modulação não trata de uma forma essencial, mas trata do controle sobre uma família de possibilidades enquadradas por parâmetros. Ela se interessa mais por amostras e previsões do que em produzir uma forma específica e bem definida derivada de um comportamento. Por fim, como a modulação trata de um molde em constante movimento, os "erros" serão cada vez mais controlados e previsíveis, para que como diz Savat, seu código genético possa vir a ajustá-los. Algo que remete ao projeto continuado e constante (meta-design), um controle específico que acontece não através da precisão, mas por meio de modulações e aproximações. Um ambiente definitivamente mais controlado, que pode ser tão sutil que se apresenta "na forma da escolha". O que este tipo de ambiente reservaria para o processo criativo do futuro? Essa seria a herança do objectile para o processo de projeto?

\section{A liberdade: objectile e as novas formas de pensar}


Cache (2011), o conceituador do objectile, destaca que o computador é uma nova força de desnaturação, ainda que se resuma basicamente a duas ações: calcular e memorizar. $\mathrm{O}$ arquiteto atual pode produzir suas próprias ferramentas de criação provavelmente como nunca na história, e o mundo digital com seus modelos matemáticos amplificam imensamente o cálculo a disposição deste. O pensador francês destaca que este mundo, com a troca de elétrons por fótons, definitivamente soltará os freios da velocidade de cálculo. Assim, poder-se-á calcular todos os movimentos, um a um, por exemplo, de um jogo de xadrez, mas o projeto não se trata de um jogo de xadrez. Talvez uma comparação mais próxima, devida a sua complexidade, seja a música (comparados por Gane, 2004 e Cache, 2011), que não se consegue explorar todas as alternativas através de princípios combinatórios. O sonho de Marin Mersenne em Harmonie Universelle (1637), o de encontrar a música perfeita através da análise de combinações, revela que a harmonia não é definida completamente de modo único. Assim não há como comparar modulações musicais, ou arquitetônicas, do mesmo modo que se poderá fazer com os movimentos de xadrez (Cache, 2011). O que isso significa? Trabalhar com o controle do cálculo algoritmo das variações e associações não servirá exatamente para alcançar o projeto mais perfeito. Não será essa a missão do objectile.

Cache (2011) recorre ao teorema da incompletude de Gödel para destacar que o importante é o elemento incalculável do pensamento, proposições que não podem ser demonstradas nem negadas. A compreensão é uma atividade nãoalgorítmica do cérebro, para entender profundamente algo seria necessário conhecer o que escapa ao seu algoritmo (Cache, 2011). Mas então qual seria a função deste objeto variável no processo de projeto, com a força de transpassar por diversos trabalhos projetuais? Cache comenta que se os computadores calculam e memorizam, o resultado real de sua invenção poderá ser o de libertar o pensamento humano dos algoritmos e da necessidade de memorizar as coisas. Com um pensamento semelhante ao de André Leroi-Gourhan, quem sugeriu que foi após o homem andar de pé que se abriu o caminho para a vocalização e para fala, o ser humano agora estaria preparado para novos tipos de pensar. Em outras palavras, do mesmo modo que a posição vertical libertou as mandíbulas humanas das funções utilitárias para buscar novas funções, o computador calculando e memorizando por nós abriria campo para novas funções da mente. Ele sugere novas e estranhas faculdades como a amnésia e a inconsciência algorítmica (Cache, 2011). O objectile, atravessando os processos de projeto, teria uma finalidade maior, liberar a mente.

\section{Conclusão}

Nossa reflexão proposta aqui, entre controle e liberdade, não visa apontar qualquer mártir, até mesmo porque controle não é prisão e liberdade não significa necessariamente descontrole. Afinal, novas ferramentas são para produzir novos conceitos, não por acaso Cache atribui um valor de desnaturação ao computador. O projeto paramétrico não possui uma qualidade inerente que assegure uma melhor concepção, sua principal característica é adicionar um novo tipo de controle, que junto aos algoritmos generativos, podem produzir cálculos que libertem nossa mente para novas aventuras. Do mesmo modo, o objectile com sua variabilidade não significa um processo melhor de trabalho, ele apenas aponta para um outro tipo de projeto em consonância com uma ambição da sociedade de controle. A visão de Gane (2004), um projeto "para pensar primeiro e acima de tudo", revela claramente que esta idéia de projeto proposta aqui, um meta-processo, é apenas parte da questão. Como lembra Cache (2011), afinal a codificação é apenas metade da história.

Gane (2004) também destaca que a emoção somente surgirá se o projetista estiver sempre em guardapara deixar-se surpreendercom os resultados significativos criados, contudo, este "em guarda" também terá que conviver, como disse Cache (2011), com uma espécie de "amnésia". Talvez o alerta do controle constante será apenas parte da contribuição que estes objectiles possam ofertar. Como lembra Kandinsky, o perigo da expressão matemática é que ela pode ficar para trás da experiência emocional e limitá-la (apud Cache, 2011), por outro lado as surpresas necessitam também que a nossa capacidade faça os cálculos ficarem limitados.

Enfim, o objectile poderá transformar como entendemos o projeto, uma incorporação da variabilidade contínua, que nos leva a pensar em meta-processos e meta-projetos. O projeto necessitará desenvolver técnicas mais compatíveis com a variação de comportamento da sociedade (também a arquitetura, mas este se remete ao terceiro caso), para que novos significados brotem. Contudo, o objectile também produzirá o superject (o sujeito relacionado ao novo objeto), um sujeito de perspectivas tão variadas quanto à multiplicidade do objectile. Novas perspectivas para novos pensamentos. Neste sentido o objectile é apenas parte do processo, não a ambição final, além do mais, ele nunca foi realmente projeto de nada em específico.

\section{Agradecimientos}

Agradeço a CAPES pelo fomento ao doutorado o qual este artigo mantém relação.

\section{Referencias}

Baudrillard, J (2004). O sistema dos objetos. São Paulo: Perspectiva.

Cache, B. (1995) Earth Moves: The Furnishing of Territories. Cambridge, Massachusetts: The MIT Press.

Cache, B. (2011). Projectiles. London: Architectural Association.

Cache, B. \& Girad, C. (2013). Objectile: The Pursuit of Philosophy by Other Means? Introduction: A Conversation between Bernard Cache and Christian Girard. In Frichot, H. \& Loo, St. (Eds.) Deleuze and Architecture. Edinburgh: Edinburgh University Press, 96-110.

Carpo, M. (2011a). The alphabet and the algorithm. Cambridge/ Massachusetts: MIT Press.

Carpo, M. (2011b). Del alfabeto al algoritmo: Sobre la autoría digital y el diseño paramétrico. Arquitectura Viva. África Esencial. Modernidad y tradición: un viaje por seis geografías. Madrid, n. 140, p.112.

Deleuze, G. (1991) A dobra: Leibniz e o Barroco. Campinas: Papirus editora. 
SIGraDi 2016, XX Congreso de la Sociedad Ibero-americana de Gráfica Digital

9-11, November, 2016 - Buenos Aires, Argentina

Deleuze, G. (1992) Post-Scriptum, sobre as sociedades de controle. In: DELEUZE, Gilles. Conversações (1972-1990). São Paulo: Editora 34, 209-219.

Deleuze, G. (2007) Pintura: el concepto de diagrama. Buenos Aires: Cactus.

Duarte, R. (2015). El diagrama arquitectónico despues de Deleuze: estudio de casos holandeses. Tese de doutorado, ETSAB-UPC, Barcelona.

Fischer, G. \& Herrmann, T. (2015) "Meta-Design: Transforming and Enriching the Design and Use of Socio-Technical Systems" in D. Randall, K. Schmidt, \& V. Wulf (Eds.), Designing Socially Embedded Technologies: A European Challenge, p. (forthcoming). http://I3d.cs.colorado.edu/ gerhard/papers/2014/EUSSET.pdf.

Gane, V. (2004) Parametric Design: A Paradigm Shift?, Master's Thesis, MIT, Cambridge.

García R. \& Jofre J. (2012) The Control of Shape: Origins Of Parametric Design In Architecture, METUJournal of Faculty of Architecture V.2012, pp. 107-118, Middle East Technical University: Ankara.

Gross, M. (1986) Design as exploring constraints, Ph.D. Thesis, MIT, Cambridge.

Hartoonian, G.(2006). Crisis of the Object: The Architecture of Theatricality. London: Routledge.
Kwinter, S. (2003). ¿Quién teme al formalismo? In: Foreing Office Architects. Filogénesis: Las especies de FOA. Barcelona: Actar, 9699.

Montaner, M. J. (2008). Crisis del objeto. In. Josep Montaner. Sistemas arquitectónicos contemporáneos. Barcelona. Gustavo Gili.

Montefameglio, A. (2016, May 30). Thauma - \#3 Objectile: Deleuze, Leibniz and Bernard Cache. May 30, 2016. Momus: Literature \& Philosophy, Others. http://www.aegeemomus.eu/2016/05/30/thauma3-objectile-deleuze-leibniz-and-bernard-cache/

Nilsson, F. (2007, May) "Architectural Objectiles: Architecture, form, meaning and experience in the digital era". Architecture \& Phenomenology International Conference. Proceedings CD. Downloaded from: http://publications.lib.chalmers.se/publication/46116

Rowe, C. \& Koetter, F. (1980). Crisis of the Object: Predicamento of Texture. Perspecta. Vol. 16 (1980), 108-141.

Savat, D. (2009) Deleuze's Objectile: From Discipline to Modulation. In: SAVAT, David e POSTER, Mark (ed.). Deleuze and New Technology. Edinburgh: Edinburgh University Press, 2009, p.45-63.

Trummer, P. (2011). Associative Design: from type to population. In: A. Menges e S. Ahlquist (Eds.). Computational Design Thinking: Computation Design Thinking. London: Wiley AD Reader, 179-194. 